\title{
Effects on heart rate variability of metoprolol supplementary to ongoing ACE-inhibitor treatment in Type I diabetic patients with abnormal albuminuria
}

\author{
E. Ebbehøj ${ }^{1}$, P.L. Poulsen ${ }^{1}$, K.W. Hansen ${ }^{1}$, S.T. Knudsen ${ }^{1}$, H. Mølgaard ${ }^{2}$, C.E. Mogensen ${ }^{1}$ \\ ${ }^{1}$ Medical Department M (Diabetes and Endocrinology), Kommunehospitalet, Aarhus University Hospital, ${ }^{2}$ Department \\ of Cardiology, Skejby Hospital, Aarhus University Hospital, Denmark
}

\begin{abstract}
Aims/hypothesis. Diabetic nephropathy is associated with a high risk of cardiac mortality including sudden death. This is presumably related to an imbalance between sympathetic and parasympathetic tone resulting in a decreased heart rate variability (HRV). In nondiabetic patients a decreased HRV is known to be a strong predictor of cardiovascular death. Studies in non-diabetic patients have shown that $\beta$-blockers improve HRV parameters known to reflect parasympathetic function. The aim of our study was to investigate effects of additional $\beta$-blocker treatment on: cardiac autonomic function, blood pressure, and urine albumin excretion in ACE-inhibitor treated Type I (insulin-dependent) diabetes mellitus patients with abnormal albuminuria.

Methods. We studied the effects of 6 weeks treatment with metoprolol (100 mg once daily, zero order kinetics formulation) in 20 patients participating in a randomised, placebo controlled, double blind, crossover trial. Patients were simultaneously monitored under ambulatory conditions with 24-h Holter-monitoring,
\end{abstract}

24-h ambulatory blood pressure recording, and 24-h fractionated urine collections. Heart rate variability was assessed by four different methods; ambulatory HRV analysis was carried out by spectral and time domain analysis, and on days of investigation short-term spectral analysis and bed-side tests were carried out.

Results. Metoprolol treatment improved in vagal tone assessed by short-term spectral analysis. The 24-h ambulatory HRV analysis showed improvement in some parameters reflecting vagal function. A minor decrease in daytime diastolic blood pressure was shown, no alterations in diurnal variation of blood pressure or urine albumin excretion were observed.

Conclusion/interpretation. These preliminary findings indicate that $\beta$-blocker treatment could improve autonomic function in Type I diabetic patients with abnormal albuminuria and an associated high risk of cardiovascular disease. [Diabetologia (2002) 45:965-975]

Keywords ACE-inhibitor $\beta$-blocker, diabetic autonomic neuropathy 24-h ambulatory blood pressure, heart rate variability, spectral analysis, time domain analysis, urine albumin excretion.
Received: 15 January 2002 / Revised: 4 March 2002

Published online: 6 June 2002

C) Springer-Verlag 2002

Corresponding author: Dr. E. Ebbehøj, Medical Department M (Diabetes and Endocrinology), Aarhus Kommunehospitalet, DK-8000 Aarhus Denmark, E-mail: e.ebbehoj@dadlnet.dk Abbreviations: AMBP, Ambulatory blood pressure; CCVHF, coefficient of component variance for HF; CCVLF, coefficient of component variance for LF; HF, square root of power of the high frequency oscillation; HF power, power of the high frequency oscillation; HRV, heart rate variability; HRV index, geometric index of total variability in a $24 \mathrm{~h}$ period; I-E diff, difference in heart rate between inspiration and expiration; LF, square root of power of the low frequency oscillation; LF power, power of the low frequency oscillation; Mean RR, mean of all normal RR intervals; Mean RR D-N, difference between awake and sleep time in mean RR; RSA, respiratory sinus arrhythmia; SDANN, standard deviation of the mean RR in all 5 min segments in a $24 \mathrm{~h}$ period; SDNN, standard deviation of all normal RR intervals; SDNN index, mean of SD's calculated on 5 min of RR intervals during a $24 \mathrm{~h}$ period; SE, standard error; sNN6\%, number of successive RR interval differences $>6 \%$, standardized to $24 \mathrm{~h}$; sNN50, number of successive RR interval differences $>50 \mathrm{~ms}$, standardized to $24 \mathrm{~h}$; UAE, urine albumin excretion. 
Diabetic autonomic neuropathy, nephropathy, and hypertension are strongly correlated clinical conditions. The severity of parasympathetic neuropathy gradually increases with increasing urine albumin excretion (UAE) [1] and increasing night:day blood pressure ratios [2]. Even in strictly normoalbuminuric, normotensive, Type I (insulin-dependent) diabetes mellitus interactions between autonomic function, UAE and blood pressure variation are evident [3]. Recent knowledge about circadian variations of sympathovagal balance, blood pressure and UAE in Type I diabetic patients has increased. Several studies suggest that in Type I diabetic patients with autonomic neuropathy the impaired diurnal blood pressure variation is associated with a relative nocturnal predominance of sympathetic activity $[4,5]$. This might represent a risk factor for cardiovascular disease and a possible explanation for the increased incidence of myocardial infarction during the night in diabetic patients [6]. Theoretically, treatment with a drug that restrains the predominant sympathetic activity might yield protection to the heart. A considerable obstacle to the use of $\beta$-blocking agents in diabetic patients concerns possible blunting of the autonomic warning symptoms of hypoglycaemia or even by potentiating hypoglycaemia induced by antidiabetic agents $[7,8,9]$. Nevertheless, there is increasing evidence, that the use of $\beta_{1}$-receptor selective blockers is not a potential risk factor for hypoglycaemia in diabetic patients $[10,11,12,13,14]$.

In non-diabetic patients a reduced HRV is known to be a strong and independent predictor of cardiac mortality $[15,16,17]$. The importance of $\beta$-blockers in the treatment of patients with acute myocardial infarction is well established [18]. Several studies have dealt with the effects of $\beta$-blocker treatment on HRV in healthy subjects [19] and in non-diabetic patients with cardiovascular disease $[20,21,22,23]$. The studies agree in showing an improvement in parameters known to reflect cardiac vagal activity. This is interpreted as being a part of the cardioprotective effect of $\beta$-blocking agents. The cardiac protective effect of $\beta$-blocker treatment after myocardial infarction is even more pronounced in diabetic patients [24].

In diabetic patients with microalbuminuria treatment with ACE-inhibitors (ACE-i) is known to reduce albuminuria, impede progression to overt nephropathy [25, 26, 27], and preserve GFR [28].The importance of strict blood pressure control in diabetic patients is well established $[29,30]$ and often combination therapy is necessary to obtain normotension [31]. Thus, the combination of ACE-i and $\beta$-blockers in patients with a high risk of cardiovascular disease seems well motivated. Only a few studies have dealt with this issue $[32,33,34,35]$ and none have focussed on the possible effects of the combination treatment on HRV. The aim of our study was to investigate the effects on HRV, BP variation and UAE of supplementary $\beta$-blockade to ACE-inhibitor treated Type I diabetic patients with abnormal albuminuria.

Table 1. Clinical characteristics

Sex (men/women)

Age (years)

BMI $\left(\mathrm{kg} / \mathrm{m}^{2}\right)$

Insulin dose geometric mean $\times / \div$ tolerance factor (units/kg body weight)

Diabetes duration (years)

Auscultatoric BP start (sys/dia) $(\mathrm{mmHg})$

Ramipril dose (mg)

ACE-inhibitor treatment duration (years)

UAE geometric mean $\times / \div$ tolerance factor $(\mu \mathrm{g} / \mathrm{min})$

Serum-creatinine $(\mu \mathrm{mol} / \mathrm{l})$ (range)

$\mathrm{HbA}_{1 \mathrm{c}}(\%)$

Smoking status (non-smoking/smoking)

Physical activity (not active/active)

Mean \pm SD, except when indicated

\section{Subjects and methods}

Patients. Inclusion criteria: (i) age between 18 to 60 years, (ii) Type I diabetes with a duration of at least five years, (iii) intact hypoglycaemia awareness, (iv) microalbuminuria or macroalbuminuria (UAE $\geq 20 \mu \mathrm{g} / \mathrm{min}$ in three overnight urine collections) despite ongoing ACE-i treatment for at least 6 months prior to inclusion, (v) no evidence of heart disease or other chronic diseases by history, physical examination or 12 lead electrocardiogram, (vi) auscultatoric BP of less than or equal to $160 / 90 \mathrm{mmHg}$, (vii) serum-creatinine concentrations of less than $150 \mu \mathrm{mol} / \mathrm{l}$, and (viii) no current (or earlier) antihypertensive treatment apart from ACE-inhibitors and diuretics.

The study included 20 Type I diabetic patients whose characteristics at baseline are given (Table 1 ). During the study period all patients were treated with the same ACE-inhibitor (Ramipril, Astra Zeneca, Albertslund, Denmark). In addition to insulin and ACE-inhibitor treatment five patients received diuretics (furosemide/thiazid). No alterations in medication were made during the study period. Patients were graded as nonsmokers (without daily use of tobacco for at least a year) or smokers (regular tobacco consumption) based on a questionnaire with confirmatory determinations of s-cotinine. All nonsmokers had undetectable s-cotinine. Furthermore patients were classified according to participation in leisure-time physical activity as: passive (not participant) or active (regular physical exercise).

The study was approved by the ethics committee of the county of Aarhus and The National Medical Board. Patients gave their written informed consent before participating. The study was monitored by the GCP-unit (Good Clinical Practice Unit) at Aarhus University Hospital.

Study design. A randomised, placebo controlled, double blind, crossover trial studying the effects of 6 weeks treatment with metoprolol $100 \mathrm{mg}$ once daily (Selo-Zok, zero order kinetics formulation, Astra Zeneca, Albertslund, Denmark) in addition to ongoing ACE-i treatment. A 4-week wash-out period was interposed between the two treatment periods. Before and after the first treatment period, and after the second treatment period patients were simultaneously monitored under ambulatory conditions with 24-h AMBP, 24-h Holter-monitoring, and 24-h fractionated urine collections. Patients were provided with three urine collection bottles and collected urine in daytime, 
night-time, and daytime according to their sleeping patterns. At days of investigation blood samples were collected, shortterm spectral analysis, and three conventional cardiovascular reflex tests were carried out. Patients underwent a clinical examination including a 12 lead ECG prior to the run-in period, treatment periods one and two, after treatment with $50 \mathrm{mg}$ of placebo/metoprolol for 3 days, and again after 1 week of treatment with $100 \mathrm{mg}$ placebo/metoprolol ensuring that the patients did not have any serious side effects.

Methods. By time domain analysis the RR interval variability was quantified by statistical parameters like the standard deviation, geometric indexes, and threshold counts [36]. Spectral analysis is a frequency domain analysis where the RR interval variability is decomposed. The technique identifies the possible systematic oscillations that may be in the variations and quantifies their intensity: high frequency (HF) oscillation, with a center frequency around $0.25 \mathrm{~Hz}$, is considered a pure estimate of parasympathetic activity $[37,38,39,40]$. The second variability component, the low frequency (LF) oscillation has an average cycle time of $0.10 \mathrm{~Hz}$. This component reflects both parasympathetic and sympathetic modulation of heart rate and is strongly influenced by baroreflex activity [38, 41, 42]. A possible impact of mean RR level on the amplitude of HF and LF components can be corrected for by calculating CCVHF (coefficient of component variance for HFpower= square root of HFpower/mean RR) $\times 100$ and CCVLF (coefficient of component variance for LFpower=square root of LFpower/mean RR) $\times 100[39,43]$. The LF:HF ratio is considered an indicator of sympatovagal balance [36], however this concept has been questioned recently [44].

The different approaches evaluate different aspects of autonomic function and integrity. The tests are not interchangeable as estimates of autonomic function but seem to be complementary [45]. We therefore chose to use a broad spectrum of autonomic tests. Two tests were carried out under strictly specified conditions (bed-side tests and short-term spectral analysis in supine and upright positions), and two tests were carried out under ambulatory conditions reflecting modulations of HRV in patients' everyday life (24-h time domain analysis and 24-h frequency domain analysis).

Bed-side tests. Three conventional cardiovascular reflex tests were carried out: Heart rate response to standing up (30:15 ratio), heart rate response to deep breathing (inspiration-expiration difference, average of the two measurements), and blood pressure response to standing up [46].

Short-term spectral analysis - supine and upright. Short-term spectral analysis was carried out about $10 \mathrm{am}$ in a quiet room with dim light and a room temperature between 20 and $22^{\circ} \mathrm{C}$. Patients did not eat, drink, or smoke $2 \mathrm{~h}$ before the examination. They rested for $15 \mathrm{~min}$ in supine position followed by RR interval measuring using an online telemetric transmitter (VariaPulse TF3; Sima Media, Olomouc, Czech Republic [47]). RR intervals were obtained in three positions (supine-standing-supine) each of at least $5 \mathrm{~min}$, resulting in 256 consecutive artefact-free heart beats for each position. RR intervals in each data set were automatically extracted using a recognition algorithm and visually scrutinised for ventricular ectopic beats. The shortterm spectral analysis was carried out using a modified fast Fourier transformation (coarse-graining) which allows the extraction of broadband non-harmonic noise, contaminating particularly the lower frequencies (1/f components)[48]. The distribution of the power and central frequency of LF $(0.05-0.15 \mathrm{~Hz})$ and HF power $(0.15-0.50 \mathrm{~Hz})$ were assessed. The LF:HF ratio, CCVHF, and CCVLF were calculated. 24-h Holter monitoring. Ambulatory electrocardiograms of $24 \mathrm{~h}$ were recorded by a Reynolds Tracker two-channel tape recorder (Reynolds Medical, Hertford, UK). For each tape the signal quality was tested and checked for speed errors immediately after the $24 \mathrm{~h}$ recording was completed. The Holter monitoring was repeated if any technical problems were disclosed.

Each recording was split into daytime and night-time according to individually reported sleeping patterns and a heart rate trend curve. The typical heart rate pattern in the period from being awake to sleep and vice versa were included in daytime and accordingly nighttime consisted of pure sleeping time. Treatment modalities were kept blind when analysing the tapes and the analysis was carried out when all participants had completed the investigation.

24- $h$ time domain analysis. The 24-h ambulatory electrocardiograms were analysed using the Pathfinder 600 system (Reynolds Medical, Hertford, UK). All periods with non-sinus beats or possible artifacts were omitted. Each QRS complex was detected and the RR intervals assessed. The mean RR interval and the difference between night and day heart rate were assessed in addition to: SDNN, standard deviation of all normal RR intervals; SDANN, standard deviation of the mean RR in all 5-min segments in a 24-h period; SDNN index, mean of SD's calculated on 5 min of RR intervals during a 24-h period; sNN6\%, number of successive RR interval differences greater than $6 \%$, standardised to $24 \mathrm{~h}$; sNN50, number of successive $\mathrm{RR}$ interval differences greater than $50 \mathrm{~ms}$, standardised to $24 \mathrm{~h}$ and HRV index, geometric index of total variability in a 24-h period.

24-h spectral analysis. As the Pathfinder 600 system does not offer a sufficiently high sampling rate necessary for valid HRV spectral analysis replay, QRS detection, measurement of the RR interval was carried out using the Reynolds Pathfinder II system (Reynolds Medical) and our own software, executed on a personal computer. The performance of this system with regard to RR interval detection [49] and HRV analysis has been validated [50]. The replay unit uses a phaselock loop system and a speed surveyor by which speed errors that might influence RR interval variability measurements can be excluded. Only cycles with normal beat morphology were used for analysis. A filter, discharging all intervals deviating more than $25 \%$ from the preceding interval, was used [49]. The 24-h RR-interval file was divided into consecutive 5-min segments. RR intervals were time equidistantly sampled at $4 \mathrm{~Hz}$ using an IPFM (integral pulse frequency modulation) algorithm [51, 52] and linear interpolation was used for periods with invalid data. After editing, at least $70 \%$ of each 5 -min segment should be available for HRV analysis to qualify. After antialiasing, the files were down-sampled to $1 \mathrm{~Hz}$, and high-pass filtered with a lower limit of $0.04 \mathrm{~Hz}$ because signals below this threshold were considered as noise [52]. The 24-h power spectral analysis is based on a parametric, autoregressive method [52]. Mean $\mathrm{RR}$, distribution of power, and central frequency of LF and HF components were assessed, and CCVHF was calculated. Results were shown as 24-h, day and night values.

24-h AMBP. The 24-h AMBP was measured by Spacelab 90207 (Redmond, Washington, USA) using an oscillometric technique. Readings were obtained every $20 \mathrm{~min}$. Day and night BP were calculated on hourly average values based on sleeping times applied from the Holter analysis.

Urine albumin excretion. Urine albumin was measured by a radioimmunoassay [53]. Baseline UAE was expressed as the geometric mean of three overnight urine samples collected 
Table 2. Bed-side tests

\begin{tabular}{|c|c|c|c|c|c|c|}
\hline & & Run-in & Placebo & Metoprolol & $\Delta$ & $p$ value \\
\hline Supine & $\begin{array}{l}\text { systolic BP }(\mathrm{mmHg}) \\
\text { diastolic BP }(\mathrm{mmHg})\end{array}$ & $\begin{array}{c}133 \pm 13 \\
80 \pm 9\end{array}$ & $\begin{array}{r}134 \pm 17 \\
82 \pm 10\end{array}$ & $\begin{array}{r}131 \pm 17 \\
78 \pm 10\end{array}$ & $\begin{array}{l}1.7 \pm 1.7 \\
2.8 \pm 1.2\end{array}$ & $\begin{array}{l}\text { NS } \\
0.024\end{array}$ \\
\hline Upright & $\begin{array}{l}\text { systolic BP }(\mathrm{mmHg}) \\
\text { diastolic BP }(\mathrm{mmHg})\end{array}$ & $\begin{array}{c}132 \pm 13 \\
81 \pm 8\end{array}$ & $\begin{array}{r}133 \pm 17 \\
82 \pm 10\end{array}$ & $\begin{array}{c}126 \pm 15 \\
78 \pm 7\end{array}$ & $\begin{array}{l}5.4 \pm 2.6 \\
2.7 \pm 1.3\end{array}$ & $\begin{array}{l}0.044 \\
0.045\end{array}$ \\
\hline BP change & $\begin{array}{l}\text { Systolic }(\mathrm{mmHg}) \\
\text { Diastolic }(\mathrm{mmHg})\end{array}$ & $\begin{array}{l}1.2 \pm 11.4 \\
0.75 \pm 6.4\end{array}$ & $\begin{array}{l}0.7 \pm 12.1 \\
0.4 \pm 5.6\end{array}$ & $\begin{array}{l}5.2 \pm 11.7 \\
0.1 \pm 5.9\end{array}$ & $\begin{array}{r}3.7 \pm 2.2 \\
0.05 \pm 1.1\end{array}$ & $\begin{array}{l}\mathrm{NS} \\
\mathrm{NS}\end{array}$ \\
\hline \multicolumn{2}{|l|}{$30: 15$ ratio } & $1.21 \pm 0.23$ & $1.13 \pm 0.14$ & $1.22 \pm 0.34$ & $0.06 \pm 0.05$ & NS \\
\hline \multicolumn{2}{|c|}{ Inspiratory-expiratory difference (beats/min) } & $14.3 \pm 11.3$ & $15.9 \pm 11.4$ & $11.7 \pm 8.5$ & $3.3 \pm 0.9$ & 0.001 \\
\hline
\end{tabular}

$\Delta$, Estimated treatment effect $\pm \mathrm{SE}$

Mean \pm SD

within a week [54]. To obtain fractionated urine collections patients were provided with three labelled urine collection bottles and collected urine in daytime, night-time, and daytime according to their sleeping pattern, giving a total of $24 \mathrm{~h}$. Patients received verbal and written information about the procedures. Urine samples were checked for infection (Multistix 8SG, Ames, Stokes Court, UK). Women were informed to refrain from urine collection when menstruating.

Blood samples. Blood glucose was measured (Reflolux II; Boehringer Mannheim, Mannheim, Germany) immediately before short-term spectral analysis was carried out. $\mathrm{HbA}_{1 \mathrm{c}}$ was assessed by HPLC (non-diabetic range 4.4-6.4\%). Serum-cotinine was measured by double antibody RIA (Nicotine metabolite, KCTD1, Medi-Lab, Copenhagen).

Statistical methods. Variables with skewed distributions were transformed to approximate normal distribution. Due to convention short-term spectral data were natural log transformed and $24-\mathrm{h}$ spectral analysis data and UAE were $\log _{10}$ transformed.

We used a compound symmetry model, which has identical correlations between each pair of observations on the same individual. The analysis of each of the response variables was carried out as a linear mixed model. The fixed effects included both factors induced by the cross-over design as well as other possible explaining factors and variables (age, smoking, etc). The cross-over design with a run-in period was modelled by means of four terms (effects); treatment, period, allocation group, and carry-over (period by treatment effect). The possible explaining variables were screened by adding them one at a time to the model together with their interaction with treatment. Thus the effect of treatment might depend on age, smoking, etc. The Bonferroni method was used to adjust the $p$ values. Results are expressed as means \pm SD, UAE is shown as geometric mean $\times / \div$ tolerance factor. $\Delta$ denominates the estimate of the treatment effect \pm SE. A two tailed $p$ value of less than 0.05 was considered statistically significant.

\section{Results}

None of the patients reported symptoms of diabetic autonomic neuropathy (orthostatic hypotension, gastric symptoms, intermittent diarrhoea, bladder dysfunction, erectile impotence, or gustatory sweating).
Patient compliance was high and was assessed by tablet counting, as $95.9 \% \pm 4.5 \%$ of the delivered tablets were taken. One patient received only $50 \mathrm{mg}$ tablets in both treatment periods due to bradycardia. The combination treatment was well tolerated, and all patients completed the trial. None of the patients experienced any hypoglycaemic episodes during the study period.

The statistical analysis showed no period, allocation group, or carry-over effect. No period effect was found which implies that there was no statistical difference between the run-in period and the placebo period results.

Bed-side tests for cardiovascular autonomic neuropathy. An abnormal or borderline deep-breathing test was carried out in 14 patients; six patients had an abnormal or borderline 30:15 ratio test (cut points according to [46]), and five patients showed an abnormal or borderline test result in both tests. None of the 20 patients tested had an abnormal orthostatic test.

The effects of supplementary metoprolol treatment on bed-side measures of autonomic function are shown in Table 2 . In the supine position systolic BP was not statistically altered by metoprolol treatment, whereas diastolic BP in the supine position as well as systolic and diastolic BP in the upright position were reduced by metoprolol treatment. The changes in systolic and diastolic BP from supine to the upright position did not change during metoprolol treatment. Metoprolol reduced the I-E diff measured in beats per $\min (p=0.001)$. The $30: 15$ ratio was unaltered by metoprolol treatment.

Short term spectral analysis of HRV - supine and upright position. In one case short-term spectral analysis was not carried out (metoprolol-results) due to low blood glucose (below $3.5 \mathrm{mmol} / \mathrm{l}$ ). Results were analysed for the individual positions (supine-standingsupine) as well as repeated measurements (Table 3). Values of HF power were increased by metoprolol treatment in both supine and upright positions. The in- 
Table 3. Short-term spectral measures of HRV

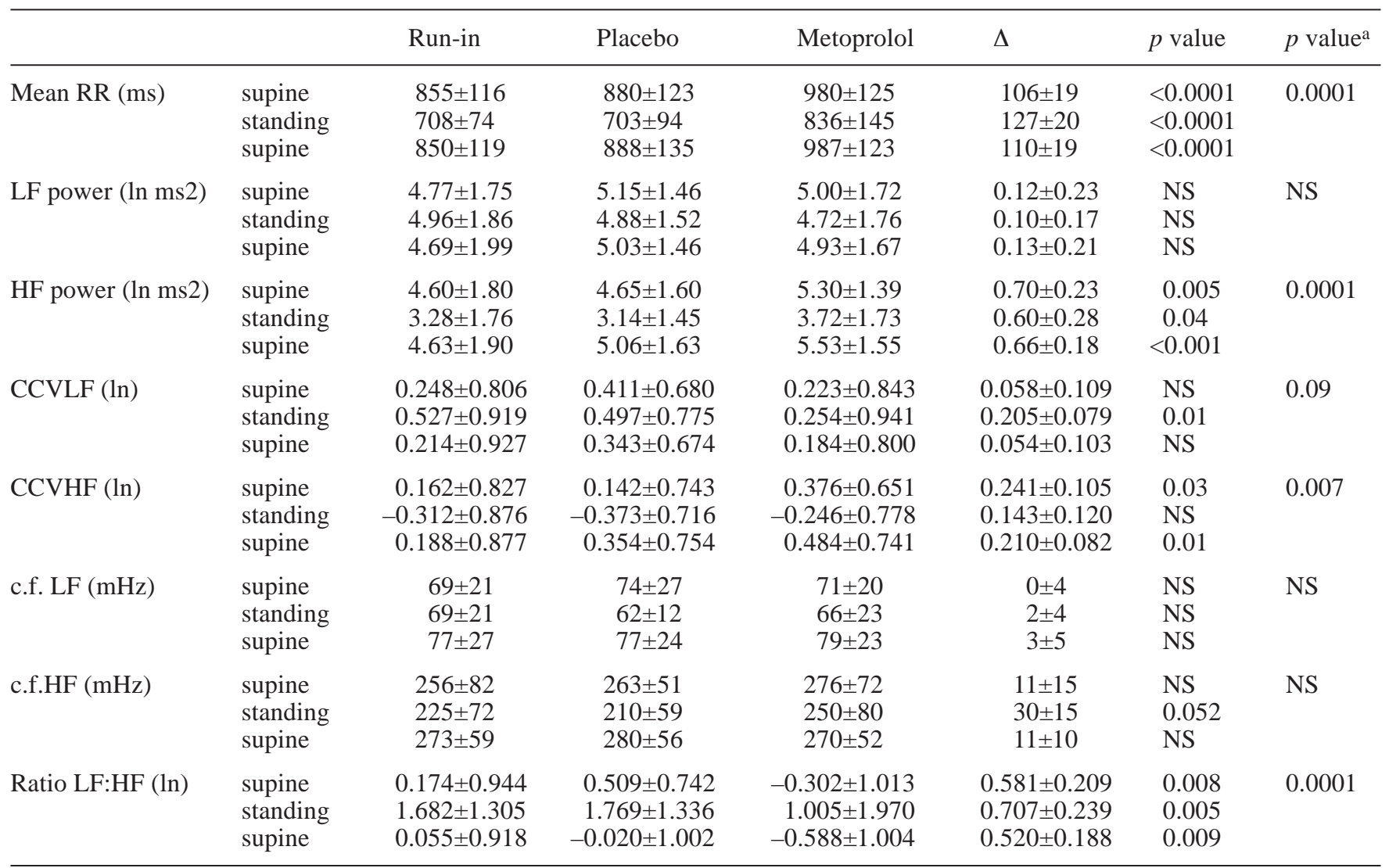

${ }^{\text {a Repeated measurements }}$

Mean \pm SD

$\Delta$, Estimated treatment effect $\pm \mathrm{SE}$

Table 4. 24-h time domain measures of HRV

\begin{tabular}{|c|c|c|c|c|c|}
\hline & Run-in & Placebo & Metoprolol & $\Delta$ & $p$ value \\
\hline Mean RR(ms) & $734 \pm 80$ & $727 \pm 70$ & $842 \pm 105$ & $111 \pm 15$ & $<0.0001$ \\
\hline Mean RR D-N (ms) & $-166 \pm 64$ & $-162 \pm 70$ & $-127 \pm 81$ & $37 \pm 13$ & 0.008 \\
\hline SDNN (ms) & $113 \pm 34$ & $114 \pm 39$ & $109 \pm 37$ & $5 \pm 6$ & NS \\
\hline SDANN (ms) & $106 \pm 33$ & $107 \pm 39$ & $98 \pm 34$ & $8 \pm 6$ & NS \\
\hline SDNN index (ms) & $40 \pm 16$ & $39 \pm 15$ & $46 \pm 19$ & $6 \pm 2$ & 0.003 \\
\hline
\end{tabular}

$\Delta$, Estimated treatment effect $\pm \mathrm{SE}$

Mean \pm SD

crease in CCVHF during metoprolol treatment was not significant in the upright position. The LF:HF ratio was increased by going to the upright position, mainly due to a drop in HF in the upright position. During metoprolol treatment the ratios were lower in both positions due to higher HF values. Measures reflecting sympatovagal modulation of the heart rate (LF power and CCVLF) were not influenced by metoprolol treatment when testing for repeated measurements while when testing for individual positions, $\mathrm{CCVLF}_{\text {standing }}$ was found to be reduced. The centre frequencies of both oscillations were unaltered during $\beta$-blockade.

$24 \mathrm{~h}$ time domain analysis of HRV. Due to technical problems three patients had the tape recording repeated with a time delay of 24 hours compared to their $24 \mathrm{~h} \mathrm{AMBP}$. Total analysed time was $20.4 \pm 2.1 \mathrm{~h}$, night-time was amounted to $6.2 \pm 1.2 \mathrm{~h}$ (Table 4). Metoprolol treatment resulted in an increment in mean $\mathrm{RR}$ interval. This was more pronounced during daytime than night-time resulting in a reduction in mean 
Table 5. 24-h Frequency domain measures of HRV

\begin{tabular}{|c|c|c|c|c|c|c|}
\hline & & Run-in & Placebo & Metoprolol & $\Delta$ & $p$ value \\
\hline Mean RR (ms) & $\begin{array}{l}24 \mathrm{~h} \\
\text { Day-time } \\
\text { Night-time }\end{array}$ & $\begin{array}{l}753 \pm 84 \\
704 \pm 79 \\
861 \pm 110\end{array}$ & $\begin{array}{l}743 \pm 77 \\
696 \pm 71 \\
846 \pm 101\end{array}$ & $\begin{array}{l}845 \pm 100 \\
816 \pm 102 \\
941 \pm 122\end{array}$ & $\begin{array}{r}97 \pm 15 \\
116 \pm 16 \\
88 \pm 16\end{array}$ & $\begin{array}{l}<0.0001 \\
<0.0001 \\
<0.0001\end{array}$ \\
\hline LF power $(\log \mathrm{ms})$ & $\begin{array}{l}24 \mathrm{~h} \\
\text { Day-time } \\
\text { Night-time }\end{array}$ & $\begin{array}{l}1.12 \pm 0.27 \\
1.10 \pm 0.28 \\
1.14 \pm 0.28\end{array}$ & $\begin{array}{l}1.13 \pm 0.24 \\
1.12 \pm 0.24 \\
1.16 \pm 0.27\end{array}$ & $\begin{array}{l}1.16 \pm 0.27 \\
1.14 \pm 0.27 \\
1.19 \pm 0.32\end{array}$ & $\begin{array}{l}0.03 \pm 0.02 \\
0.04 \pm 0.02 \\
0.04 \pm 0.03\end{array}$ & $\begin{array}{l}\text { NS }(0.07) \\
\text { NS }(0.07) \\
\text { NS }(0.09)\end{array}$ \\
\hline CCVHF (log) & $\begin{array}{l}24 \mathrm{~h} \\
\text { Day-time } \\
\text { Night-time }\end{array}$ & $\begin{array}{r}-0.07 \pm 0.18 \\
-0.10 \pm 0.17 \\
-0.002 \pm 0.23\end{array}$ & $\begin{array}{l}-0.05 \pm 0.18 \\
-0.09 \pm 0.17 \\
0.007 \pm 0.20\end{array}$ & $\begin{array}{l}-0.03 \pm 0.16 \\
-0.05 \pm 0.16 \\
0.025 \pm 0.21\end{array}$ & $\begin{array}{l}0.03 \pm 0.027 \\
0.04 \pm 0.03 \\
0.02 \pm 0.03\end{array}$ & $\begin{array}{l}\text { NS } \\
\text { NS } \\
\text { NS }\end{array}$ \\
\hline c.f. $\mathrm{HF}(\mathrm{mHz})$ & $\begin{array}{l}24 \mathrm{~h} \\
\text { Day-time } \\
\text { Night-time }\end{array}$ & $\begin{array}{l}265 \pm 22 \\
263 \pm 19 \\
265 \pm 24\end{array}$ & $\begin{array}{l}263 \pm 28 \\
260 \pm 26 \\
264 \pm 29\end{array}$ & $\begin{array}{l}266 \pm 16 \\
268 \pm 20 \\
262 \pm 23\end{array}$ & $\begin{array}{l}2 \pm 6 \\
6 \pm 6 \\
1 \pm 3\end{array}$ & $\begin{array}{l}\text { NS } \\
\text { NS } \\
\text { NS }\end{array}$ \\
\hline
\end{tabular}

$\Delta$, Estimated treatment effect $\pm \mathrm{SE}$

Mean \pm SD

Table 6. 24-h ambulatory blood pressure data

\begin{tabular}{|c|c|c|c|c|c|c|}
\hline \multirow[t]{3}{*}{ Systolic AMBP (mmHg) } & $24 \mathrm{~h}$ & $130 \pm 11$ & $131 \pm 11$ & $129 \pm 10$ & $-1.2 \pm 1.6$ & NS \\
\hline & Day-time & $134 \pm 11$ & $135 \pm 12$ & $133 \pm 10$ & $-1.4 \pm 1.7$ & NS \\
\hline & $\mathrm{N} / \mathrm{D} \mathrm{BP}$ ratio $(\%)$ & $89.6 \pm 3.9$ & $88.4 \pm 5.7$ & $89.1 \pm 5.7$ & $0.1 \pm 1.0$ & NS \\
\hline \multirow[t]{2}{*}{ Diastolic AMBP (mmHg) } & $24 \mathrm{~h}$ & $79 \pm 8$ & $80 \pm 8$ & $77 \pm 8$ & $-1.9 \pm 1.0$ & 0.07 \\
\hline & N/D BP ratio (\%) & $84.7 \pm 5.9$ & $83.0 \pm 5.6$ & $89.1 \pm 5.7$ & $0.1 \pm 1.2$ & NS \\
\hline
\end{tabular}

$\Delta$, Estimated treatment effect $\pm \mathrm{SE}$

Mean \pm SD

RR D-N (i.e heart rate is reduced more during daytime than night-time). Measures of short-term HRV (SDNN index and sNN50) were increased by metoprolol treatment. Parameters reflecting long-term HRV (partly dependent on sympathetic neural and neurohumoural activity) like SDANN and mean RR D-N were reduced, although not statistically significant for SDANN. The broad band measures of total 24-h HRV (SDNN, HRV index) which are summations of shortterm and long-term HRV were unchanged during metoprolol treatment.

24-h frequency domain analysis of HRV. Total analysed time was $20.8 \pm 1.7 \mathrm{~h}$, night-time amounted to $6.1 \pm 1.3 \mathrm{~h}$ (Table 5). HF increased during treatment with metoprolol contrary to CCVHF, LF, and center frequencies where no statistically significant altera- tions were seen. Night:day ratios of $\mathrm{HF}$ and CCVHF also did not change during the metoprolol treatment period.

No relation between age, physical activity, sex, or BMI and HRV as assessed by short-term spectral analysis, 24-h spectral analysis, or 24-h time domain analysis was shown, nor did the effect of the metoprolol treatment depend on age, physical activity, sex, or BMI.

24-h ambulatory blood pressure. Total analysed time was $23.8 \pm 0.7 \mathrm{~h}$. (Blood pressure data are shown in Table 6). No significant changes in systolic BP values or night:day ratios were observed whereas metoprolol treatment resulted in a reduction in diastolic daytime $\mathrm{BP}$ of $2.3 \mathrm{mmHg}(p=0.04)$.

No relation between age, physical activity, sex, or $\mathrm{BMI}$ and blood pressure results was assessed, nor did 
the effect of the metoprolol treatment depend on age, physical activity, sex, or BMI.

Urine albumin excretion. One diurnal urine collection was missed due to menstruation. No alterations in UAE were observed after 6 weeks of supplementary $\beta$-blocker treatment neither in fractionated urine collections nor in diurnal urine collections $\left(\mathrm{UAE}_{\mathrm{Run}-\mathrm{in}}=\right.$ $117.7 \times / \div 3.0 \mu \mathrm{g} / \mathrm{min}, \quad \mathrm{UAE}_{\text {placebo }}=104.7 \times / \div 2.9 \mu \mathrm{g} / \mathrm{min}$, $\left.\mathrm{UAE}_{\text {Metoprolol }}=95.9 \times / \div 3.1 \mu \mathrm{g} / \mathrm{min}, \mathrm{NS}\right)$.

Lipids, HbAlc, and weight. No changes in total cholesterol, triglyceride or $\mathrm{HbA}_{1 \mathrm{c}}$ concentrations were observed during metoprolol administration. HDL cholesterol decreased $0.12 \pm 0.06 \mathrm{mmol} / \mathrm{l}(p=0.051)$. Patients experienced a weight gain of $1.02 \mathrm{~kg} \pm 0.31 \mathrm{~kg}$ ( $p=0.003)$ during metoprolol treatment.

\section{Discussion}

The most potent risk factor for accelerated cardiovascular disease and death in Type I diabetes is the development of nephropathy and a raised UAE is a hallmark of patients at high risk of developing cardiovascular disease. Although none of the patients reported symptoms of diabetic autonomic neuropathy 15 patients carried out borderline or abnormal bed-side tests indicating that the study group had reduced baseline HRV.

This study addressed effects of metoprolol treatment on HRV in Type I diabetic subjects with ongoing ACE-inhibitor treatment. The effects were assessed by two different spectral analysis methods as well as by time domain analysis and bed-side tests. The results show that HRV in diabetic patients without symptoms of cardiovascular autonomic neuropathy is susceptible to pharmacologic intervention as is the case in healthy subjects $[19,56]$, and in patients with AMI $[20,21$, 23].

Bed side tests. The I-E difference (b.p.m.), which can be considered an estimate of vagal function, decreased significantly. Similar has been observed by others [57] in non-diabetic subjects, when calculating the I-E difference in b.p.m. This finding is in contrast to the results by the other indices of pure vagal control which increased by metoprolol. However, all these latter parameters are derived from heart period calculations (milliseconds). The explanation for this apparent paradox, is the inverse and non-linear relation between heart rate and heart period (RR intervals, ms) which affects associated HRV calculations in a similar fashion. This causes opposite direction of HRV results depending on the unit of measurement, in particular when interventions that shift the mean heart rate level considerably, are studied. This methodological problem has been shown $[58,59]$.
Short-term spectral analysis - supine and upright position. Metoprolol treatment resulted in enhancement of parameters reflecting parasympathetic function, HF power and CCVHF. In contrast, others found metoprolol to decrease HRV in (Type I and Type II) diabetic patients [60]. However, the short-term spectral analysis technique which was applied is based on heart rate and not RR intervals. This opposite direction of HRV results is due to the inverse and nonlinear relation of heart rate and heart period which could push the derived HRV in opposite directions. Results from non-diabetic subjects, based on HRV calculated in $\mathrm{ms}$, find that $\beta$-blocker treatment increase parameters of vagal function [19, 20, 21, 22].

24-h time domain analysis of HRV. Metoprolol treatment prolonged the mean RR interval more during daytime than night-time resulting in a diminished mean RR D-N. Sympathetic activity is higher during daytime than night-time and this is probably the reason for the difference. It is hardly due to lower metoprolol concentrations during night-time, because similar results were found using $\beta$-blockade dosage (atenolol $50 \mathrm{mg}$ ) four times daily [19]. The overall variability during the 24-h period, SDNN, summarising both short-term and long-term variability was not affected by metoprolol treatment as shown in healthy subjects [19] and in patients with coronary artery disease [22, 61]. The failure of 24-h SDNN to confirm the other measures of heart rate variability during metoprolol treatment can be accounted for by the decrease in long-term HRV as exemplified by the decrease in mean RR D-N [19]. The short-term variation in heart rate is firmly related to vagal activity. SDNN index and sNN50, both indices of short-term variability, increased indicating an increase in vagal activity during metoprolol treatment. Part of this increase in prevalence of successive RR interval differences of more than $50 \mathrm{~ms}$ could for mathematical reasons be explained by the prolongation of RR intervals. The vagal index measuring relative changes in $R R$ interval (sNN6\%) was not altered by metoprolol treatment. These results are in accordance with previous data in non-diabetic post myocardial infarction patients treated with metoprolol $100 \mathrm{mg}$ once daily for 4 weeks [20] but disagree with other results showing an increase in both sNN50 and sNN6\% when healthy subjects were treated with atenolol $200 \mathrm{mg}$ daily for 3 to 5 days [19]. The difference between these results could be due to different dose regimes or different study groups.

24-h spectral analysis of HRV. 24-h LF component reflects both sympathetic and parasympathetic functions which makes it difficult to predict the effect of metoprolol on this parameter, whereas HF component, reflecting vagal activity, is supposed to increase. When treating healthy subjects with atenolol, an increment 
in 24-h HF as well as 24-h LF was observed [19]. This is in contrast to results from other studies, where LF power is unchanged during $\beta$-blockade $[22,39,56]$. In this study metoprolol caused a numerical but not a statistically significant increase in 24-h LF and an increase in HF throughout $24 \mathrm{~h}$. The difference in HF induced by metoprolol treatment was no longer statistically significant when correcting for the effect of mean RR level on the amplitude of HF (CCVHF). The diurnal variation of $\mathrm{HF}$, assessed by night:day ratio of $\mathrm{HF}$, remained unchanged. In this study metoprolol treatment caused a reduced mean RR D-N ratio but no alterations in diurnal variation of sympatovagal balance as assessed by night:day ratios were observed.

Short-term spectral analysis, obtained under stationary conditions in the laboratory, showed a distinct improvement in all HRV parameters reflecting vagal activity during metoprolol treatment. The $24-\mathrm{h}$ time and frequency domain analyses obtained under ambulatory conditions showed improvements in some parameters reflecting parasympathetic modulation (i.e. HF, SDNN index, and sNN50), but when corrections for the reduced heart rate were made (sNN6\% and CCVHF) the differences were no longer statistically significant. The different results cannot be explained by the dose regime as patients had short-term spectral analysis carried out in the morning before taking the metoprolol tablet. HRV analysis of 24-h recordings of RR intervals is supposed to reflect the degree of autonomic modulation rather than the autonomic tone and averages of these modulations do not represent an average level of tone [36]. This could explain the different results obtained by short-term spectral analysis in the laboratory and 24-h spectral and time domain analysis. The two spectral analysis methods applied in the study are based on different methodologies which makes a direct comparison of absolute values difficult [36].

In contrast to other findings $[52,62,63,64,65]$ this study did not show any covariation between age, physical activity, sex, or BMI and HRV parameters. Possible explanations could be, that the patients in our study consisted of a small and relatively homogenous group according to BMI and age. Furthermore the patients' level of physical activity was only assessed by a questionnaire without any test of their fitness.

24-h ambulatory blood pressure. Supplementary metoprolol treatment to ACE-inhibitor treated Type I diabetic patients reduced day-time diastolic blood pressure $(2.3 \pm 1.1 \mathrm{mmHg}, p=0.04)$. Studies concerning the antihypertensive effects of combination therapy with a $\beta$-blocker and an ACE-inhibitor in non-diabetic hypertensive patients are ambiguous $[66,67,68,69,70$, $71,72,73]$. These results must be interpreted with caution since none of the studies were carried out using AMBP. Studies concerning the combination therapy in diabetic patients are rather sparse $[32,35]$ and only one study used the AMBP technique [32]. This study did not show an additional antihypertensive effect when an ACE-inhibitor was added to ongoing $\beta$-blocker (and diuretic) treatment in 10 Type I diabetic patients with diabetic nephropathy for 4 months.

Urine albumin excretion. When studying the effects of supplementary ACE-inhibitor treatment to $\beta$-blocker treated Type I diabetic patients other studies showed a reduction in UAE $[32,35]$. In our study UAE was only moderately and insignificantly lowered by supplementary metoprolol treatment to ACE-inhibitor treated patients. This could be explained by the different study design, a shorter treatment duration, or both.

Lipids, $H b A_{l c}$, and weight. As expected patients gained weight during supplementary metoprolol treatment [74] and HDL cholesterol decreased. No change in metabolic control as assessed by $\mathrm{HbA}_{1 \mathrm{c}}$ was observed which could be attributed to the short-term treatment and the number of patients treated.

In conclusion. Our study showed, that it is possible by means of pharmacological intervention to improve HRV parameters in Type I diabetic patients with abnormal albuminuria. Supplementary metoprolol treatment caused an amelioration in all short-term HRV parameters known to reflect parasympathetic function. Parameters reflecting parasympathetic function obtained under ambulatory conditions also increased but when corrections for the slower heart rate were carried out, the difference between placebo and metoprolol treatment was not statistically significant. Supplementary metoprolol treatment caused no alterations in diurnal variation of blood pressure or UAE. A minor decrease in daytime diastolic blood pressure was achieved. In this short-term study no alteration in UAE was found.

However, our study group was small and the treatment duration relatively short. Therefore long-term prospective studies looking at morbidity and mortality are needed to evaluate the effects of $\beta_{1}$-selective $\beta$-blockers as rational adjunct drugs to ACE-inhibitor treatment in Type I diabetic patients with abnormal albuminuria and increased risk of cardiovascular events.

Acknowledgements. We are grateful to M. Møller and G. NæssSchmit for their excellent technical assistance. We thank MSc Mogens Erlandsen, Department of Biostatistics, University of Aarhus, for his statistical advise. The Novo Nordisk Foundation, The Sehested Hansen Foundation, Faculty of Health, University of Aarhus, King Christian X Foundation, The Danish Heart foundation, and Astra Zeneca are acknowledged for financial support.

\section{References}

1. Mølgaard H, Christensen PD, Sørensen KE, Christensen CK, Mogensen CE (1992) Association of 24-h cardiac parasympathetic activity and degree of nephropathy in IDDM patients. Diabetes 41:812-817 
2. Hansen KW, Mau PM, Marshall SM, Christiansen JS, Mogensen CE (1992) Circadian variation of blood pressure in patients with diabetic nephropathy. Diabetologia 35:1074 1079

3. Poulsen PL, Ebbehøj E, Hansen KW, Mogensen CE (1997) 24-h blood pressure and autonomic function is related to albumin excretion within the normoalbuminuric range in IDDM patients. Diabetologia 40:718-725

4. Spallone V, Bernardi L, Ricordi L et al. (1993) Relationship between the circadian rhythms of blood pressure and sympathovagal balance in diabetic autonomic neuropathy. Diabetes 42:1745-1752

5. Pecis M, Azevedo MJ, Moraes RS, Ferlin EL, Gross JL (2000) Autonomic dysfunction and urinary albumin excretion rate are associated with an abnormal blood pressure pattern in normotensive normoalbuminuric Type 1 diabetic patients. Diabetes Care 23:989-993

6. Hjalmarson A, Gilpin EA, Nicod P et al. (1989) Differing circadian patterns of symptom onset in subgroups of patients with acute myocardial infarction. Circulation 80:267-275

7. Sixth report of the Joint National Committee on prevention, detection, evaluation, and treatment of high blood pressure (1997) Arch Intern Med 157:24132446

8. Leese GP, Savage MW, Chattington PD, Vora JP (1996) The diabetic patient with hypertension. Postgrad Med J 72:263-268

9. Sowers JR, Epstein M (1995) Diabetes mellitus and associated hypertension, vascular disease, and nephropathy. An update. Hypertension 26:869-879

10. Viberti GC, Keen H, Bloom SR (1980) Beta blockade and diabetes mellitus: effect of oxprenolol and metoprolol on the metabolic, cardiovascular, and hormonal response to insulin-induced hypoglycemia in insulin-dependent diabetics. Metabolism 29:873-879

11. Barnett AH, Leslie D, Watkins PJ (1980) Can insulin-treated diabetics be given beta-adrenergic blocking drugs? BMJ 280:976-978

12. Shorr RI, Ray WA, Daugherty JR, Griffin MR (1997) Antihypertensives and the risk of serious hypoglycemia in older persons using insulin or sulfonylureas. JAMA 278:40-43

13. Thamer M, Ray NF, Taylor T (1999) Association between antihypertensive drug use and hypoglycemia: a casecontrol study of diabetic users of insulin or sulfonylureas. Clin Ther 21:1387-1400

14. UK Prospective Diabetes Study Group UKPDS 39 (1998) Efficacy of atenolol and captopril in reducing risk of macrovascular and microvascular complications in type 2 diabetes: BMJ 317:713-720

15. Kleiger RE, Miller JP, Bigger JT Jr, Moss AJ (1987) Decreased heart rate variability and its association with increased mortality after acute myocardial infarction. Am J Cardiol 59:256-262

16. Cripps TR, Malik M, Farrell TG, Camm AJ (1991) Prognostic value of reduced heart rate variability after myocardial infarction: clinical evaluation of a new analysis method. Br Heart J 65:14-19

17. Bigger JT Jr, Fleiss JL, Steinman RC, Rolnitzky LM, Kleiger RE, Rottman JN (1992) Frequency domain measures of heart period variability and mortality after myocardial infarction. Circulation 85:164-171

18. Yusuf S, Peto R, Lewis J, Collins R, Sleight P (1985) Beta blockade during and after myocardial infarction: an overview of the randomized trials. Prog Cardiovasc Dis $27: 335-371$
19. Cook JR, Bigger JT Jr, Kleiger RE, Fleiss JL, Steinman RC, Rolnitzky LM (1991) Effect of atenolol and diltiazem on heart period variability in normal persons. J Am Coll Cardiol 17:480-484

20. Mølgaard H, Mickley H, Pless P, Bjerregaard P, Møller M (1993) Effects of metoprolol on heart rate variability in survivors of acute myocardial infarction. Am J Cardiol 71:1357-1359

21. Sandrone G, Mortara A, Torzillo D, La Rovere MT, Malliani A, Lombardi F (1994) Effects of beta blockers (atenolol or metoprolol) on heart rate variability after acute myocardial infarction. Am J Cardiol 74:340345

22. Niemela MJ, Airaksinen KE, Huikuri HV (1994) Effect of beta-blockade on heart rate variability in patients with coronary artery disease. J Am Coll Cardiol 23:13701377

23. Kontopoulos AG, Athyros VG, Papageorgiou AA, Papadopoulos GV, Avramidis MJ, Boudoulas H (1996) Effect of quinapril or metoprolol on heart rate variability in post-myocardial infarction patients. Am J Cardiol 77:242246

24. Malmberg K, Herlitz J, Hjalmarson A, Ryden L (1989) Effects of metoprolol on mortality and late infarction in diabetics with suspected acute myocardial infarction. Retrospective data from two large studies. Eur Heart J 10:423-428

25. Mathiesen ER, Hommel E, Giese J, Parving HH (1991) Efficacy of captopril in postponing nephropathy in normotensive insulin dependent diabetic patients with microalbuminuria. BMJ 303:81-87

26. Rudberg S, Aperia A, Freyschuss U, Persson B (1990) Enalapril reduces microalbuminuria in young normotensive Type I (insulin-dependent) diabetic patients irrespective of its hypotensive effect. Diabetologia 33:470-476

27. Viberti G, Mogensen CE, Groop LC, Pauls JF (1994) Effect of captopril on progression to clinical proteinuria in patients with insulin-dependent diabetes mellitus and microalbuminuria. European Microalbuminuria Captopril Study Group. JAMA 271:275-279

28. Mathiesen ER, Hommel E, Hansen HP, Smidt UM, Parving HH (1999) Randomised controlled trial of long term efficacy of captopril on preservation of kidney function in normotensive patients with insulin dependent diabetes and microalbuminuria. BMJ 319:24-25

29. UK Prospective Diabetes Study Group UKPDS 38 (1998) Tight blood pressure control and risk of macrovascular and microvascular complications in type 2 diabetes BMJ 317:703-713

30. Hansson L, Zanchetti A, Carruthers SG et al. (1998) Effects of intensive blood-pressure lowering and lowdose aspirin in patients with hypertension: principal results of the Hypertension Optimal Treatment (HOT) randomised trial. HOT Study Group. Lancet 351:17551762

31. White WB, Prisant LM, Wright JT Jr (2000) Management of patients with hypertension and diabetes mellitus: advances in the evidence for intensive treatment. Am J Med 108:238-245

32. Pedersen MM, Hansen KW, Schmitz A, Sørensen K, Christensen CK, Mogensen CE (1992) Effects of ACE inhibition supplementary to beta blockers and diuretics in early diabetic nephropathy. Kidney Int 41:883-890

33. Mogensen CE, Pedersen MM, Ebbehøj E, Poulsen PL, Schmitz A (1997) Combination therapy in hypertensionassociated diabetic renal disease. Int $\mathrm{J}$ Clin Pract [Suppl 90]:52-58 
34. Pedersen MM, Christensen CK, Hansen KW, Christiansen JS, Mogensen CE (1991) ACE-inhibition and renoprotection in early diabetic nephropathy. Response to enalapril acutely and in long-term combination with conventional antihypertensive treatment. Clin Invest Med 14:642-651

35. Christensen CK, Pedersen MM, Mogensen CE (1990) Combining antihypertensive agents in early diabetic nephropathy. J Diabetes Complications 4:88-90

36. Task Force of the European Society of Cardiology and the North American Society of Pacing and Electrophysiology (1996) Heart rate variability. Standards of measurement, physiological interpretation, and clinical use. Eur Heart J 17:354-381

37. Katona PG, Jih F (1975) Respiratory sinus arrhythmia: noninvasive measure of parasympathetic cardiac control. J Appl Physiol 39:801-805

38. Akselrod S, Gordon D, Ubel FA, Shannon DC, Berger AC, Cohen RJ (1981) Power spectrum analysis of heart rate fluctuation: a quantitative probe of beat-to-beat cardiovascular control. Science 213:220-222

39. Hayano J, Sakakibara Y, Yamada A et al. (1991) Accuracy of assessment of cardiac vagal tone by heart rate variability in normal subjects. Am J Cardiol 67:199-204

40. Pomeranz B, Macaulay RJ, Caudill MA et al. (1985) Assessment of autonomic function in humans by heart rate spectral analysis. Am J Physiol 248:H151-H153

41. Lombardi F, Sandrone G, Pernpruner S et al. (1987) Heart rate variability as an index of sympathovagal interaction after acute myocardial infarction. Am J Cardiol 60:12391245

42. Lombardi F, Malliani A, Pagani M, Cerutti S (1996) Heart rate variability and its sympatho-vagal modulation. Cardiovasc Res 32:208-216

43. Mølgaard H, Christensen PD, Hermansen K, Sørensen KE, Christensen CK, Mogensen CE (1994) Early recognition of autonomic dysfunction in microalbuminuria: significance for cardiovascular mortality in diabetes mellitus? Diabetologia 37:788-796

44. Eckberg DL (1997) Sympathovagal balance: a critical appraisal. Circulation 96:3224-3232

45. Mølgaard H (1995) 24-hour heart rate variability. Methodology and clinical aspects. Thesis, Aarhus University, Aarhus, pp 1-72

46. Ewing DJ, Martyn CN, Young RJ, Clarke BF (1985) The value of cardiovascular autonomic function tests: 10 years experience in diabetes. Diabetes Care 8:491498

47. Salinger J, Vychodil R, Novotný J et al. (1995) Telemetric computer-aided system for non-invasive examination of heart rate variability, type VariaPulse TF3. Computers in Cardiology IEEE Proc, pp 437-440

48. Yamamoto Y, Hughson RL (1991) Coarse-graining spectral analysis: new method for studying heart rate variability. J Appl Physiol 71:1143-1150

49. Mølgaard H (1991) Evaluation of the Reynolds Pathfinder II system for $24 \mathrm{~h}$ heart rate variability analysis. Eur Heart J 12:1153-1162

50. Bjerregaard P (1982) Premature beats in healthy subjects 40-79 years of age. Eur Heart J 3:493-503

51. Berger RD, Akselrod S, Gordon D, Cohen RJ (1986) An efficient algorithm for spectral analysis of heart rate variability. IEEE Trans Biomed Eng 33:900-904

52. Mølgaard H, Hermansen K, Bjerregaard P (1994) Spectral components of short-term RR interval variability in healthy subjects and effects of risk factors. Eur Heart J 15:11741183
53. Christensen CK, Ørskov C (1984) Rapid screening PEG radioimmunoassay for quantification of pathological microalbuminuria. Diabetic Nephropathy 3:92-94

54. Mogensen CE, Chachati A, Christensen CK et al. (1985) Microalbuminuria: an early marker of renal involvement in diabetes. Uremia Invest 9:85-95

55. Wieling W, Brederode JF van, Rijk LG de, Borst C, Dunning AJ (1982) Reflex control of heart rate in normal subjects in relation to age: a data base for cardiac vagal neuropathy. Diabetologia 22:163-166

56. Pitzalis MV, Mastropasqua F, Massari F et al. (1998) Effects of hydrophilic and lipophilic beta-blockers on heart rate variability and baroreflex sensitivity in normal subjects. Pacing Clin Electrophysiol 21:559-567

57. Airaksinen KE, Niemela MJ, Huikuri HV (1994) Effect of beta-blockade on baroreflex sensitivity and cardiovascular autonomic function tests in patients with coronary artery disease. Eur Heart J 15:1482-1485

58. Sapoznikov D, Luria MH, Gotsman MS (1993) Comparison of different methodologies of heart rate variability analysis. Comput Methods Programs Biomed 41:69-75

59. Faes TJ, De Neeling NN, Kingma R, TenVoorde BJ, Karemaker JM (1995) On the quantification of heart rate changes in autonomic function tests: relations between measures in beats per minute, seconds and dimensionless ratios. Clin Sci (Colch) 89:557-564

60. Salo TM, Viikari JS, Antila KJ, Voipio-Pulkki LM, Jalonen JO, Välimäki IA (1996) Antihypertensive treatment and heart rate variability in diabetic patients: role of cardiac autonomic neuropathy. J Auton Nerv Syst 60:6170

61. Mølgaard H, Mickley H, Bjerregaard P, Møller M (1993) Metoprolol improves heart period variability in survivors of myocardial infarction. Resuscitation 25:93

62. Mølgaard H, Sørensen KE, Bjerregaard P (1991) Circadian variation and influence of risk factors on heart rate variability in healthy subjects. Am J Cardiol 68:777784

63. Coats AJ, Adamopoulos S, Radaelli A et al. (1992) Controlled trial of physical training in chronic heart failure. Exercise performance, hemodynamics, ventilation, and autonomic function. Circulation 85:2119-2131

64. Howorka K, Pumprla J, Haber P, Koller-Strametz J, Mondrzyk J, Schabmann A (1997) Effects of physical training on heart rate variability in diabetic patients with various degrees of cardiovascular autonomic neuropathy. Cardiovasc Res 34:206-214

65. Karason K, Mølgaard H, Wikstrand J, Sjostrom L (1999) Heart rate variability in obesity and the effect of weight loss. Am J Cardiol 83:1242-1247

66. Staessen J, Fagard R, Lijnen P, Verschueren LJ, Amery A (1981) The hypotensive effect of propranolol in captopriltreated patients does not involve the plasma renin-angiotensin-aldosterone system. Clin Sci (Colch) 61 [Suppl 7]:441444

67. Pickering TG, Case DB, Sullivan PA, Laragh JH (1982) Comparison of antihypertensive and hormonal effects of captopril and propranolol at rest and during exercise. Am J Cardiol 49:1566-1568

68. Franz IW, Behr U, Ketelhut R (1987) Resting and exercise blood pressure with atenolol, enalapril and a low-dose combination. J Hypertens [Suppl 5]:S37-S41

69. Belz GG, Breithaupt $\mathrm{K}$, Erb $\mathrm{K}$, Kleinbloesem $\mathrm{CH}$, Wolf GK (1989) Influence of the angiotensin converting enzyme inhibitor cilazapril, the beta-blocker propranolol and their combination on haemodynamics in hypertension. J Hypertens 7:817-824 
70. Erb KA, Breithaupt K, Kleinbloesem CH, Wolf GK, Blez GG (1990) Does the combination of cilazapril and propranolol lower blood pressure at rest and during exercise more pronouncedly than either of the two components given alone? Clin Physiol Biochem 8:3545

71. Swedish Lisinopril Study Group (1991) Lisinopril combined with atenolol in the treatment of hypertension. J Cardiovasc Pharmacol 18:457-461
72. Soininen K, Gerlin-Piira L, Suihkonen J et al. (1992) A study of the effects of lisinopril when used in addition to atenolol. J Hum Hypertens 6:321-324

73. Bursztyn M, Gavras I, Gourley L, DeSilva J, Whalen J, Gavras H (1994) Effect of combination therapy with atenolol and the angiotensin-converting enzyme inhibitor benazepril. Clin Ther 16:429-436

74. Cruickshank JM, Prichard BNC (1994) Beta blockers in clinical practice, 2nd edn. Churchill Livingstone, Edinburgh London Madrid Melbourne New York Tokyo, pp 949-957 